\title{
The Effect of Chalazion Excision on Corneal Aberrometric and Densitometric Values
}

\author{
(1) Hasan Oncul, (1) Yusuf Yildirim, (1) Mehtap Caglayan, (1) Umut Dag, (1) Mehmet Fuat Alakus \\ Department of Ophthalmology, University of Health Sciences Gazi Yasargil Training and Research Hospital, Diyarbakir, Turkey
}

\begin{abstract}
Objectives: The aim of this study was to investigate the effect of chalazion excision on corneal aberrations and corneal densitometry.

Methods: Thirty-six patients with a chalazion in I eyelid and 40 healthy subjects were included in the study. Corneal aberration parameters of total root mean square (RMS), RMS high-order aberration (HOA), horizontal trefoil, oblique trefoil, horizontal coma, vertical coma, and spherical aberration values were measured using Scheimpflug corneal topography (Pentacam HR; Oculus Optikgeräte GmbH, Wetzler, Germany). Corneal densitometry values measured from 4 regions of the cornea $(0-2,2-6,6-10$, and $10-12 \mathrm{~mm}$ ) and 4 corneal depths (anterior, central, posterior, and total) were recorded. Preoperative measurements of the patients (Group I), postoperative first-month measurements (Group 2), and control group (Group 3) measurements were compared.

Results: The total RMS measurement was $1.64 \pm 0.48 \mu \mathrm{m}$ in Group I, I.35 $\pm 0.32 \mu \mathrm{m}$ in Group 2, and I.I7 $\pm 0.38 \mu \mathrm{m}$ in Group 3 (Group 1-2: $p=0.007$, Group 1-3: $p<0.00$ I, Group 2-3: $p=0.173$ ). The mean spherical aberration value was $0.183 \pm 0.057 \mu \mathrm{m}$ in Group I, 0.157 $\pm 0.048 \mu \mathrm{m}$ in Group 2, and 0.144 $\pm 0.050 \mu \mathrm{m}$ in Group 3 (Group I-2: $\mathrm{p}=0.104$, Group I-3: $p=0.004$, Group 2-3: $p=0.78 \mathrm{I}$ ). The total corneal densitometric measurement was $15.95 \pm I .80$ gray scale units (GSU) in Group I, 14.76 $\pm 1.76 \mathrm{GSU}$ in Group 2, and 14.33 \pm I.49 GSU in Group 3 (Group 1-2: $p=0.01$, Group I-3: $p<0.001$, Group 2-3: $\mathrm{p}=0.804$ ).

Conclusion: It was observed that some corneal aberration and corneal densitometry values were higher in patients with a chalazion compared with those of healthy individuals, and there was a decrease in corneal aberration and densitometry values after surgical excision.
\end{abstract}

Keywords: Chalazion, corneal densitometry, pentacam HR

\section{Introduction}

A chalazion is a lipogranulomatous inflammation that occurs due to blockage of the secretory ducts of the meibomian glands in the eyelids and may affect all ages of people (I). Causes of meibomian gland dysfunction, such as chronic blepharitis, rosacea, and seborrheic dermatitis, are risk factors for the development of chalazion (2). Ocular disorders such as cosmetic disturbances in the eyelids, visual disturbances, foreign body sensation, and ptosis may also occur (I).

Corneal transparency is considered as an indicator of corneal health and may vary with many factors that cause corneal and endothelial dysfunction (3). Corneal transparency, which is evaluated subjectively by slit-lamp biomi-

How to cite this article: Oncul H, Yildirim Y, Caglayan M, Dag U, Alakus MF. The Effect of Chalazion Excision on the Aberrometric and Densitometric Values of the Cornea. Beyoglu Eye J 2021; 6(3): 191-199.

Address for correspondence: Hasan Oncul, MD. Saglik Bilimleri Universitesi Gazi Yasargil Egitim ve Arastirma Hastanesi, Goz Hastaliklari Anabilim Dali, Diyarbakir, Turkey

Phone: +90 5357624011 E-mail: hasan.oncul@hotmail.com

Submitted Date: December 14, 2020 Accepted Date: February 14, 2021 Available Online Date: September 27, 2021

${ }^{\oplus}$ Copyright 2021 by Beyoglu Eye Training and Research Hospital - Available online at www.beyoglueye.com OPEN ACCESS This work is licensed under a Creative Commons Attribution-NonCommercial-ShareAlike 4.0 International License. (c)(-) 
croscopy in an ophthalmic examination, has recently been evaluated quickly and objectively by utilizing the ability of light to reflect back from the corneal layers. Pentacam HR (Oculus, Wetzlar, Germany) is a non-invasive imaging method that can obtain up to 50 anterior segment crosssectional images within $2 \mathrm{~s}$ using the Scheimpflug principle. With added software, it measures corneal aberration and densitometry changes so that the effects of eye and systemic diseases on the cornea can be examined in more detail (4). Densitometry maps of the cornea are obtained by measuring the reflected rays from the corneal epithelium, stroma, and endothelium with the Scheimpflug method. These analyses, in which the scattering of the reflected rays in the optical axis is measured, can be affected by the tissue properties and structure in the path of light, such as the anatomical arrangement of the collagen fibers in the stroma and keratocytes and the extracellular matrix organization (3). Furthermore, this technique allows the measurement of corneal aberrations through optical wavefront analysis (4).

A chalazion is an inflammatory mass that can resorb spontaneously or with medical treatment. Due to mechanical compression on the cornea and limbus, distortion may develop in the cornea and may cause some topographic changes in the cornea (I). In addition to the mechanical compression effect of the chalazion, the existing inflammatory process may also affect the cornea. These changes may cause a change in corneal transparency and ultimately in optical quality. In this study, pre-operative aberrometric and densitometric values were measured in chalazion patients, and these values were compared with a healthy control group and in the post-operative period. To the best of our knowledge, there is no study in the literature evaluating the densitometric properties of the cornea before and after chalazion surgery.

\section{Methods}

This study was conducted in Diyarbakır Gazi Yaşargil Training and Research Hospital between January and October 2020. Ethics committee approval was obtained from the mentioned hospital for the study. Written informed consent forms were obtained from the patients, and the principles of the Helsinki Declaration were followed in the study.

Patients with treatment-resistant chalazion in a single eyelid for at least I month were included in the study. The control group consisted of healthy individuals who did not have any ocular and/or systemic disease that could affect corneal measurements. Patients with a history of ocular surgery, a history of ocular trauma, who wore contact lenses, who displayed the presence of a corneal scar, anterior segment, lens, vitreous and macular pathology, and those with systemic diseases likely to cause changes in corneal densitometry were excluded from the study. A detailed examination, including visual examination with Snellen chart (20 feet), best-corrected visual acuity, tonometry, slit-lamp biomicroscopic examination, and dilated fundus examination, was performed in all patients. The presence of dry eye and corneal punctate staining was investigated, as it may affect the corneal densitometry measurement of all participants. The Schirmer I test (without local anesthesia) was applied to detect the presence of dry eye (Color Bar, Eagle Vision, Memphis, TN). After 5 min, wetting less than $5 \mathrm{~mm}$ was accepted as severe dry eye; 5-10 $\mathrm{mm}$ as mild dry eye; and wetness $\geq 10 \mathrm{~mm}$ was considered normal. The presence of punctate epitheliopathy was evaluated by corneal staining using a fluorescein strip (Haag-Streit, Köniz, Switzerland). Patients with chalazion with a Schirmer I test greater than $10 \mathrm{~mm}$ and without punctate style epithelial staining on the cornea were included in the present study. Topographic, aberrometric, and densitometric measurements of the cornea were made with Pentacam HR (Oculus $\mathrm{GmbH}$, Wetzlar, HE, Germany). Measurements were made preoperatively and in the post-operative $\mathrm{I}^{\text {st }}$ month. Pre-operative chalazion patients were categorized as Group I, post-operative chalazion patients as Group 2, and healthy controls as Group 3. Furthermore, corneal measurements were made according to site of chalazion (upper eyelid/lower eyelid).

Measurements made with Pentacam HR were performed by the same experienced physician (X.X) in a dark room (without a window) in the drafting room with standard lighting (4 lux) during the same time of day (2:00-4:00 p.m.), without dilating the pupil. Patients whose extraction quality was not approved by the device were not included in the study. The average of values obtained from two consecutive shots was entered into the database. For corneal densitometry, the random density units (gray scale unit) of the rays scattered back from the cornea were expressed with results ranging from a minimum of 0 (maximum transparency) to a maximum of 100 (minimum transparency-total corneal opacity) (5). To obtain corneal densitometry data, the $12 \mathrm{~mm}$ diameter area of the cornea was divided into four concentric zones: $0-2,2-6,6-10$, and $10-12 \mathrm{~mm}$. Cornea depth was obtained from four different zones: The anterior surface $(120 \mu \mathrm{m})$, the posterior $(60 \mu \mathrm{m})$, the stromal layer in between, the central part, and the whole cornea layer. To evaluate corneal aberrations, wavefront measurements were made with Pentacam $\mathrm{HR}$ from the $6 \mathrm{~mm}$ zone so that the pupil size did not affect the measurements. With Zernike analyses, total root mean square (RMS), RMS high-order aberration (HOA), trefoil $0^{\circ}$ (horizontal), trefoil $30^{\circ}$ (oblique), coma $0^{\circ}$ (horizontal), coma $90^{\circ}$ (vertical), and spherical aberration values were recorded.

\section{Surgical Method}

Local anesthesia was provided with $2 \%$ lidocaine. The lesion was localized with the help of chalazion forceps, and the stability of the eyelid and lesion was achieved by reversing 
the eyelid. The chalazion mass was reached with a vertical transconjunctival incision with the $\mathrm{I}^{\text {th }}$ scalpel. The mass content and the chalazion capsule were completely curetted with the chalazion curette, and the wound was left for primary healing without suturing. Printed closure was performed for I day, and topical antibiotic steroid drops and antibiotic pomade were prescribed.

\section{Statistical Analysis}

The Statistical Package for the Social Sciences (SPSS) 20.0 software for Windows (SPSS Inc., Chicago, Illinois, USA) was used to analyze the outcomes. The compatibility of the data with normal distribution was checked with the Kolmogorov-Smirnov test. Quantitative variables were reported as mean \pm standard deviation. An independent t-test was used to compare categorical variables between the sides of chalazion. A one-way analysis of variance (ANOVA) was used to compare the studied parameters of the three groups. The Bonferroni post hoc test was used to determine differences between the groups. The Bonferroni correction for post hoc analysis in ANOVA was performed. Furthermore, $p<0.05 / 3$ $=0.016$ was considered statistically significant in the Bonferroni pairwise tests. For all other comparisons, $\mathrm{p}<0.05$ was considered statistically significant.

\section{Results}

Thirty-six patients with chalazion in one eye and 40 healthy controls were included in this study. Whereas the male/female ratio was II/25 in patients with chalazion, it was I4/25 in the control group. Furthermore, the mean age of patients with chalazion was $24.9 \pm 11.3$ years, and it was $23.6 \pm 7.8$ years in the control group. There was no statistical difference between the groups in terms of age and gender $(p>0.05)$.

There was chalazion in the right eye of 14 patients and in the left eye of 22 patients. The lesion was in the upper eyelid in 20 patients and in the lower eyelid in 16 patients. The Schirmer I test revealed results of $16.7 \pm 2.7 \mathrm{~mm}$ in Group I, $17.7 \pm 2.7 \mathrm{~mm}$ in Group 2, and $20.5 \pm 3.1 \mathrm{~mm}$ in Group 3. Furthermore, the difference between the groups was statistically significant (Groups I-2: $p=0.347$, Groups I-3: $p \leq 0.00$ I, and Groups 2-3: $p \leq 0.001)$.

Total RMS measurements were $1.64 \pm 0.48 \mu \mathrm{m}$ in Group I, I. $35 \pm 0.32 \mu \mathrm{m}$ in Group 2, and I.17 $\pm 0.38 \mu \mathrm{m}$ in Group 3 (Groups I-2: $p=0.007$, Groups 1-3: $p \leq 0.001$, and Groups 2-3: $p=0.173$ ). Spherical aberration values were measured as $0.183 \pm 0.057 \mu \mathrm{m}$ in Group I, $0.157 \pm 0.048 \mu \mathrm{m}$ in Group 2, and $0.144 \pm 0.050 \mu \mathrm{m}$ in Group 3 (Groups I-2: $p=0.104$, Groups 1-3: $p=0.004$, and Groups 2-3: $p=0.78 \mathrm{I})$. Where-

Table I. The comparison of corneal aberration measurements of preoperative chalazion, postoperative chalazion, and the healthy control group

\begin{tabular}{|c|c|c|c|c|c|}
\hline & $\begin{array}{c}\text { Group I } \\
\text { (Preoperative) } \\
(n=36)\end{array}$ & $\begin{array}{c}\text { Group } 2 \\
\text { (Postoperative) } \\
(n=36)\end{array}$ & $\begin{array}{c}\text { Group } 3 \\
(\text { Control) } \\
(n=40)\end{array}$ & $\mathbf{p}^{*}$ & $\mathbf{p}^{\dagger}$ \\
\hline \multirow{2}{*}{ Total RMS $(\mu \mathrm{m})$} & & & & & $|-3:<0.00|$ \\
\hline & & & & & $2-3: 0.173$ \\
\hline & & & & & $2-3: 0.781$ \\
\hline Trefoil & $0.060 \pm 0.112$ & $0.121 \pm 0.102$ & $-0.03 I \pm 0.067$ & $<0.001$ & I-2: $0.29 \mid$ \\
\hline \multirow[t]{2}{*}{ Horizontal $(\mu \mathrm{m})$} & & & & & $|-3:<0.00|$ \\
\hline & & & & & $2-3: 0.051$ \\
\hline Coma & $0.484 \pm 0.146$ & $0.413 \pm 0.166$ & $0.001 \pm 0.172$ & 0.391 & \\
\hline \multicolumn{6}{|l|}{ Horizontal $(\mu \mathrm{m})$} \\
\hline \multirow[t]{3}{*}{ Coma Vertical $(\mu \mathrm{m})$} & $0.720 \pm 0.199$ & $-0.063 \pm 0.200$ & $-0.004 \pm 0.163$ & 0.011 & I-2: 0.009 \\
\hline & & & & & I-3: 0.245 \\
\hline & & & & & 2-3:0.520 \\
\hline
\end{tabular}


Table 2. The comparison of corneal densitometry values of preoperative chalazion, postoperative chalazion, and healthy control group

\begin{tabular}{|c|c|c|c|c|c|}
\hline & $\begin{array}{c}\text { Group I } \\
\text { (Preoperative) } \\
(n=36)\end{array}$ & $\begin{array}{c}\text { Group } 2 \\
\text { (Postoperative) } \\
(n=36)\end{array}$ & $\begin{array}{c}\text { Group } 3 \\
\text { (Control) } \\
(n=40)\end{array}$ & $\mathbf{p}^{*}$ & $\mathbf{p}^{\dagger}$ \\
\hline \multicolumn{6}{|c|}{ 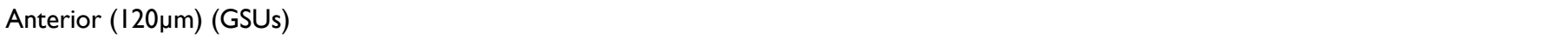 } \\
\hline $0-2 \mathrm{~mm}$ & $20.88 \pm 1.38$ & $20.35 \pm 1.04$ & $19.77 \pm 0.89$ & $<0.00$ I & $|-3:<0.00|$ \\
\hline $2-6 \mathrm{~mm}$ & $19.64 \pm 1.30$ & $19.23 \pm 0.60$ & $18.79 \pm 1.62$ & 0.015 & I-3:0.0I I \\
\hline $6-10 \mathrm{~mm}$ & $18.91 \pm 1.82$ & $18.09 \pm 0.87$ & $17.59 \pm 1.85$ & 0.002 & $1-3: 0.001$ \\
\hline \multirow[t]{2}{*}{$10-12 \mathrm{~mm}$} & $27.47 \pm 3.55$ & $23.39 \pm 2.87$ & $21.95 \pm 3.59$ & $<0.001$ & $1-2: 0.012$ \\
\hline & & & & & $|-3:<0.00|$ \\
\hline \multirow[t]{3}{*}{ Total } & $21.71 \pm 3.08$ & $19.98 \pm 3.73$ & $19.03 \pm 1.59$ & $<0.001$ & $\mathrm{I}-2: 0.039$ \\
\hline & & & & & $|-3:<0.00|$ \\
\hline & & & & & $2-3: 0.478$ \\
\hline \multicolumn{6}{|c|}{ Central (GSUs) } \\
\hline $0-2 \mathrm{~mm}$ & $|3.00 \pm 0.8|$ & $12.68 \pm 0.89$ & $|2.45 \pm 0.7|$ & 0.013 & $I-3: 0.00 \mid$ \\
\hline $2-6 \mathrm{~mm}$ & $11.72 \pm 0.62$ & II. $.46 \pm 0.58$ & II. $30 \pm 0.60$ & 0.010 & I-3: 0.008 \\
\hline \multirow[t]{2}{*}{$6-10 \mathrm{~mm}$} & $12.50 \pm 1.56$ & || $.7 \mid \pm 1.04$ & $11.13 \pm 0.84$ & $<0.001$ & $1-2: 0.016$ \\
\hline & & & & & $|-3:<0.00|$ \\
\hline $10-12 \mathrm{~mm}$ & $17.86 \pm 3.87$ & $15.94 \pm 2.39$ & $15.12 \pm 2.93$ & 0.001 & $|-3: 0.00|$ \\
\hline \multirow[t]{3}{*}{ Total } & $13.40 \pm 1.70$ & $12.95 \pm 2.00$ & $12.24 \pm 1.33$ & 0.012 & I-2: 0.773 \\
\hline & & & & & $1-3: 0.010$ \\
\hline & & & & & $2-3: 0.213$ \\
\hline \multicolumn{6}{|c|}{ Posterior $(60 \mu \mathrm{m}) \quad$ (GSUs) } \\
\hline $0-2 \mathrm{~mm}$ & $10.97 \pm 0.87$ & $10.81 \pm 0.74$ & $10.59 \pm 0.68$ & 0.100 & \\
\hline $2-6 \mathrm{~mm}$ & $10.34 \pm 0.65$ & $10.14 \pm 0.42$ & $9.94 \pm 0.69$ & 0.017 & $1-3: 0.013$ \\
\hline $6-10 \mathrm{~mm}$ & $11.46 \pm 1.26$ & $11.10 \pm 1.69$ & $10.4 \mid \pm 0.79$ & 0.002 & I-3: 0.002 \\
\hline $10-12 \mathrm{~mm}$ & $13.95 \pm 2.92$ & $13.11 \pm 2.94$ & $\mid 2.21 \pm 1.98$ & 0.018 & $1-3: 0.014$ \\
\hline \multirow[t]{3}{*}{ Total } & $11.29 \pm 1.23$ & $10.98 \pm 1.19$ & $10.62 \pm 1.20$ & 0.055 & $\mathrm{I}-2: 0.800$ \\
\hline & & & & & I-3: 0.049 \\
\hline & & & & & $2-3: 0.596$ \\
\hline \multicolumn{6}{|l|}{ Total (GSUs) } \\
\hline \multirow[t]{3}{*}{$0-2 \mathrm{~mm}$} & $|5.0| \pm 0.96$ & $|4.73 \pm| . \mid 4$ & $14.35 \pm 1.26$ & 0.043 & I-2:0.039 \\
\hline & & & & & I-3:0.873 \\
\hline & & & & & $2-3: 0.458$ \\
\hline $2-6 \mathrm{~mm}$ & $13.62 \pm 0.86$ & $|3.33 \pm 0.9|$ & $12.94 \pm 1.04$ & 0.008 & I-3: 0.006 \\
\hline \multirow[t]{2}{*}{$6-10 \mathrm{~mm}$} & $14.25 \pm 3.00$ & $12.95 \pm 1.10$ & $12.40 \pm 0.90$ & $<0.001$ & $I-2: 0.013$ \\
\hline & & & & & $|-3:<0.00|$ \\
\hline $10-12 \mathrm{~mm}$ & $20.74 \pm 2.58$ & $18.74 \pm 3.89$ & $17.43 \pm 3.00$ & 0.009 & I-3: 0.007 \\
\hline \multirow[t]{3}{*}{ Total } & $15.95 \pm 1.80$ & $\mid 4.76 \pm 1.76$ & $14.33 \pm 1.49$ & $<0.001$ & $I-2: 0.010$ \\
\hline & & & & & $|-3:<0.00|$ \\
\hline & & & & & 2-3:0.804 \\
\hline
\end{tabular}

Results are denoted as mean \pm standard deviation. GSU: Gray Scale Units. *: One-way analysis of variance (ANOVA); $p<0.05$ statistically significant. ${ }^{\dagger}:$ Bonferroni Post-hoc test; $p<0.016$ statistically significant. (Bold value indicates statistically significant). 
as the difference in trefoil horizontal and coma vertical aberrations between the groups was significant $(p<0.00 I$ and $p=0.0 \mathrm{I}$, respectively), there was no significant difference between trefoil oblique and coma horizontal aberrations $(p=0.024$ and $p=0.39 \mathrm{I}$, respectively) (Table I).

Corneal densitometry values in the anterior region were $21.71 \pm 3.08$ in Group I, 19.98 \pm 3.73 in Group 2, and 19.03 \pm 1.59 in Group 3 (Groups 1-2: $p=0.039$, Groups I-3: $p \leq 0.00$ I, and Groups 2-3: $p=0.478$ ). Corneal densitometry values in the central region were $13.40 \pm 1.70$ in Group I, 12.95 \pm 2.00 in Group 2, and 12.24 I. 33 in Group 3 (Groups 1-2: $p=0.773$, Groups 1-3: $p=0.0$ I, and Groups 2-3: $p=0.213)$. In the posterior region, it was $1 \mathrm{I} .29 \pm 1.23$ in

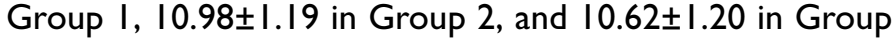
3 , and the difference was not significant $(p=0.055)$. When the total corneal densitometric measurements were evaluated, it was I5.95 \pm 1.80 in Group I, I4.76 I I.76 in Group 2, and I4.33 \pm 1.49 in Group 3 (Groups I-2: $p=0.01$, Groups I-3: $\mathrm{p} \leq 0.00 \mathrm{I}$, and Groups 2-3: $\mathrm{P}=0.804)$. Chalazion patients had higher densitometry values compared to the healthy group. Besides, a statistically significant decrease was observed in the anterior $(10-12 \mathrm{~mm})$, central $(6-10$ $\mathrm{mm}$ ), and total corneal densitometry values in the post-operative period (Table 2). Pre- and post-operative corneal densitometry images of a patient with chalazion are shown in Figure $\mathrm{l} a$ and $\mathrm{b}$.
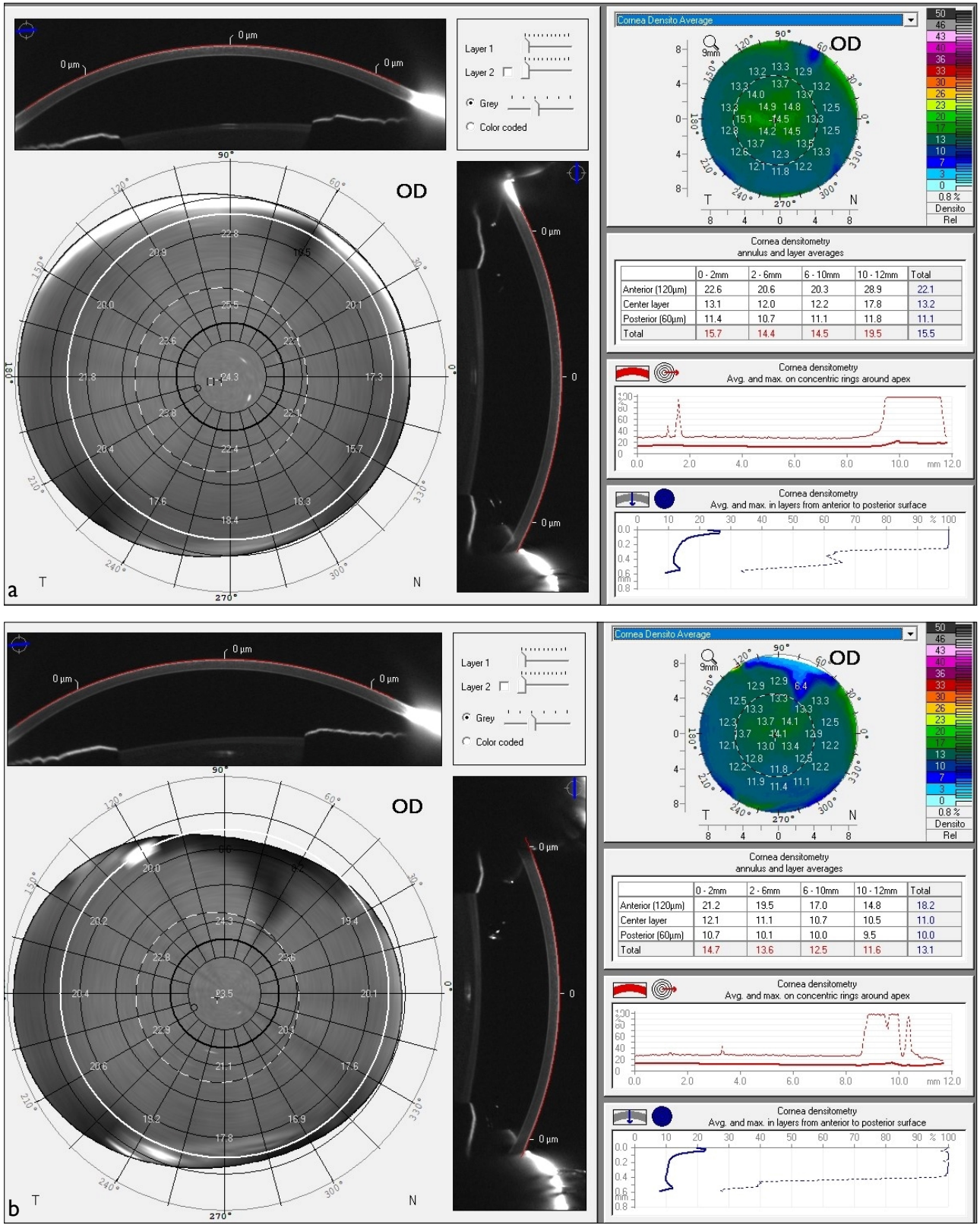

Figure I. (a) Preoperative corneal densitometry images of a patient with chalazion. (b) Corneal densitometry images of a patient with chalazion at first month postoperatively. 
Table 3. Corneal aberration measurements according to site of chalazion

\begin{tabular}{lccc} 
& $\begin{array}{c}\text { Upper eyelid group } \\
(\mathbf{n}=\mathbf{2 0})\end{array}$ & $\begin{array}{c}\text { Lower eyelid group } \\
(\mathbf{n = 1 6 )}\end{array}$ & $\mathbf{p}^{*}$ \\
\hline Total RMS $(\mu \mathrm{m})$ & $1.79 \pm 0.42$ & $1.45 \pm 0.48$ & $\mathbf{0 . 0 3 5}$ \\
Spherical Aberration $(\mu \mathrm{m})$ & $0.172 \pm 0.064$ & $0.197 \pm 0.045$ & 0.192 \\
Trefoil Horizontal $(\mu \mathrm{m})$ & $0.079 \pm 0.086$ & $0.035 \pm 0.138$ & 0.283 \\
Trefoil Oblique $(\mu \mathrm{m})$ & $-0.001 \pm 0.086$ & $-0.069 \pm 0.120$ & 0.067 \\
Coma Horizontal $(\mu \mathrm{m})$ & $0.077 \pm 0.173$ & $0.012 \pm 0.098$ & 0.168 \\
Coma Vertical $(\mu \mathrm{m})$ & $0.172 \pm 0.064$ & $0.064 \pm 0.205$ & 0.087
\end{tabular}

RMS: Root mean square $\mu \mathrm{m}$ : micron meters. Results are denoted as mean \pm standard deviation. *: Independent t-test; $\mathrm{p}<0.05$ statistically significant. (Bold value indicates statistically significant).

In corneal aberration, measurements made according to site of chalazion, while there was a statistical difference in total RMS measurements ( $p=0.035)$, there was no difference in spherical aberration, trefoil horizontal, trefoil oblique, coma horizontal, and coma vertical values $(p=0.192, p=0.283$, $p=0.067, p=0.168$, and $p=0.087$; respectively) (Table 3 ).

When the corneal densitometry values of the patients with chalazion in the upper and lower eyelids were compared, no statistically difference was found in the central $(p=0.08)$ and posterior region $(p=0.542)$, while the anterior and total corneal densitometry values were higher in patients with chalazion in the upper eyelid, and the difference was statistically significant $(p=0.039$ and $p=0.032$; respectively) (Table 4).

\section{Discussion}

The etiopathogenesis in chalazion formation remains uncertain. The host inflammatory response against the infectious agent occurs when the infectious agent and/or its metabolites activate the humoral and cellular response (6). It is known that some preparative factors that cause chalazion formation in chalazion patients may cause dry eye formation. The Schirmer I test and corneal fluorescein staining are frequently used to determine the presence and severity of dry eyes. In dry eye, confocal biomicroscopy has shown an increase in the density of inflammatory cells in the corneal epithelium and hyperreflective keratocytes, possibly induced by inflammatory mediators $(7,8)$. It has also been reported that dry eye may affect optical visual quality by changing optical aberrations (9). Researchers have reported that the presence of punctate epitheliopathy in patients with dry eyes further increases the corneal densitometry value (10). However, Fukuoka et al. (II) reported that there was a decrease in the Schirmer test in chalazion patients compared to the healthy control group, but this difference was not significant. Chalazion patients with a Schirmer I test score $<10 \mathrm{~mm}$ and/ or punctate staining on the cornea were excluded in the current study because it might affect the corneal densitometry measurements. However, even in this case, Schirmer I test values were lower than in the control group. This may be associated with the concomitant presence of meibomian gland dysfunction, ocular surface disorder, chronic blepharitis, tear instability, and complex inflammatory processes in chalazion patients, which are all involved in the etiopathogenesis of dry eye.

Not all regions of the cornea have the same biomechanical properties. Whereas the collagen in the cornea is arranged in an inferior-superior and nasal-temporal manner, it shows a tangential course in the limbus (12). In addition, elastic differences in the cornea are less in the cornea paracentral and periphery but greatest in the limbus (13). This situation causes the cornea to respond differently to mechanical effects. In several previous studies, it was revealed that the chalazion resulted in changes in corneal astigmatism and aberrations due to the effect of mechanical compression (14-16). In addition, it has been reported that chalazion may cause an increase in intraocular pressure and that a decrease in intraocular pressure would be achieved after excision (17). It has been stated that lesions on the upper eyelid, involving the central eyelid and that are $>5 \mathrm{~mm}$, have a greater effect on corneal astigmatism and aberrations. Therefore, early excision of these lesions is recommended (14-16).

Corneal aberrations are related to the image quality of the retina. Increases in ocular aberrations result in a decrease in optical visual quality due to the development of glare, halo, and distortion (18). It is known that the increased eyelid pressure caused by the lesion effect in the chalazion increases HOAs (16). Sabermoghaddam et al. (16) reported a decrease in ocular aberrations after excision in patients with upper eyelid chalazion. Jin et al. (I5) reported that vertical astigmatism, oblique astigmatism, and total RMS aberrations were higher in the upper eyelid compared to lesions in 
Table 4. Corneal densitometry values according to site of chalazion

\begin{tabular}{|c|c|c|c|}
\hline & $\begin{array}{l}\text { Upper eyelid group } \\
\qquad(n=20)\end{array}$ & $\begin{array}{l}\text { Lower eyelid group } \\
\qquad(n=16)\end{array}$ & $\mathbf{p}^{*}$ \\
\hline \multicolumn{4}{|c|}{ 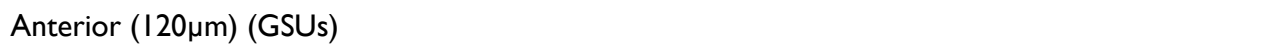 } \\
\hline $0-2 \mathrm{~mm}$ & $21.06 \pm 1.47$ & $20.65 \pm 1.28$ & 0.378 \\
\hline $2-6 \mathrm{~mm}$ & $19.81 \pm 1.48$ & $19.44 \pm 1.04$ & 0.398 \\
\hline $6-10 \mathrm{~mm}$ & $19.48 \pm 1.97$ & $18.20 \pm 1.37$ & 0.028 \\
\hline $10-12 \mathrm{~mm}$ & $26.50 \pm 1.12$ & $24.53 \pm 2.77$ & 0.015 \\
\hline Total & $22.00 \pm 1.45$ & $21.06 \pm 1.19$ & 0.039 \\
\hline \multicolumn{4}{|l|}{ Central (GSUs) } \\
\hline $0-2 \mathrm{~mm}$ & $13.03 \pm 0.85$ & $12.96 \pm 0.78$ & 0.807 \\
\hline $2-6 \mathrm{~mm}$ & II. $.74 \pm 0.72$ & $11.70 \pm 0.50$ & 0.864 \\
\hline $6-10 \mathrm{~mm}$ & $12.69 \pm 1.98$ & $12.27 \pm 0.77$ & 0.391 \\
\hline $10-12 \mathrm{~mm}$ & $18.12 \pm 5.03$ & $16.77 \pm 1.33$ & 0.263 \\
\hline Total & $|3.8| \pm 2.16$ & $12.89 \pm 0.55$ & 0.080 \\
\hline \multicolumn{4}{|c|}{ Posterior $(60 \mu \mathrm{m})$ (GSUs) } \\
\hline $0-2 \mathrm{~mm}$ & $10.86 \pm 0.72$ & $11.11 \pm 1.03$ & 0.405 \\
\hline $2-6 \mathrm{~mm}$ & $10.30 \pm 0.62$ & $10.39 \pm 0.70$ & 0.677 \\
\hline $6-10 \mathrm{~mm}$ & $11.58 \pm 1.60$ & $|I .3| \pm 0.64$ & 0.508 \\
\hline $10-12 \mathrm{~mm}$ & $13.72 \pm 3.75$ & $|4.25 \pm| .4 \mid$ & 0.561 \\
\hline Total & $11.19 \pm 1.50$ & $1 \mathrm{I} .43 \pm 0.78$ & 0.542 \\
\hline \multicolumn{4}{|l|}{ Total (GSUs) } \\
\hline $0-2 \mathrm{~mm}$ & $|5.06 \pm| .0 \mid$ & $|4.95 \pm 0.9|$ & 0.746 \\
\hline $2-6 \mathrm{~mm}$ & $13.68 \pm 1.02$ & $13.55 \pm 0.63$ & 0.643 \\
\hline $6-10 \mathrm{~mm}$ & $14.80 \pm 3.92$ & $13.58 \pm 0.80$ & 0.190 \\
\hline $10-12 \mathrm{~mm}$ & $21.62 \pm 5.90$ & $19.88 \pm 1.59$ & 0.221 \\
\hline Total & $16.27 \pm 1.73$ & $15.28 \pm 0.74$ & 0.032 \\
\hline
\end{tabular}

Results are denoted as mean \pm standard deviation. GSU: Gray Scale Units. : Independent t-test; $p<0.05$ statistically significant. (Bold value indicates statistically significant).

the lower eyelid. In the present study, it was observed that total RMS, spherical aberration, and trefoil horizontal aberration values were higher in patients with chalazion compared to the healthy control group. In these patients, there was a significant decrease in total RMS and coma vertical aberrations after surgery. In the studies mentioned above, only patients with chalazion in the upper eyelid were evaluated. However, in the present study, aberrometric evaluation was performed in patients with chalazion in the lower and upper eyelids. Total RMS values were found to be higher in patients with chalazion in the upper eyelid. Considering the effects of changes in corneal aberrations on optic quality, especially upper eyelid lesions, should be excised at an early stage.

Many studies have reported that there may be changes in corneal keratometry and refraction in patients with chalazion. However, it is known that these changes do not affect corneal densitometry measurements $(19,20)$. Therefore, refractive and keratometric changes observed in the chalazion are not seen as a confounding factor in corneal densitometry measurement in this study.

The Pentacam Scheimpflug system is a superior imaging method in many aspects than light biomicroscopy in detecting corneal pathologies. Corneal densitometric measurements are made with the addition of a new software to the Pentacam HR device; thus, objective, fast, and reproducible data are obtained $(2 \mathrm{I}, 22)$. With this imaging method, possible densitometric changes can be detected even in corneas that appear completely transparent clinically. A healthy cornea does not normally absorb visible light, so the light distribution is minimal (3). However, proteoglycans surrounding the keratocyte and collagen fibrils in the cornea and disorders in the extracellular matrix organization may decrease 
vision quality due to increased light backscatter (23). The increases in corneal density are not necessarily related to the decrease in vision; such increases are thought to be related to decrease visual quality (24).

There is still no consensus on what constitutes normal values in corneal densitometry. Whereas the total corneal densitometry value was measured as $19.74 \pm 3.89$ in a study of 445 healthy participants (5), it was measured as $14.4 \pm 2.74$ in another study with 588 participants (19). In the present study, the total corneal densitometry value was $15.95 \pm 1.80$ in chalazion patients and $14.33 \pm 1.49$ in the healthy control group. It was observed that corneal densitometry values were $14.76 \pm 1.76$ in the post-operative $I^{\text {st }}$ month, and the decrease in these patients after surgical excision was significant. Furthermore, results revealed that corneal densitometric changes in the chalazion occurred more frequently in the anterior and central areas compared to the posterior area. This result may relate to the lower density of keratocytes in the posterior layer.

One or more mechanisms may have caused the increase in corneal densitometry in patients with chalazion. Normal cornea distributes light predominantly at the air-tear film and tear film corneal interface; therefore, the change in the refractive index of light in the anterior is highest (25). The inflammatory process in chalazion, mechanical irritation on the ocular surface, conjunctival inflammation, and the pre-ocular tear film layer imbalance may have caused an increase in densitometry values. Tanaka et al. (26) stated that conjunctival inflammation might lead to the development of corneal damage. In the chalazion, a conjunctival inflammatory process occurs against the infectious agent, its toxins and mediators, and this process is accompanied by a host response in the limbus. Subclinical keratocyte activation develops through the activation of pro-inflammatory cytokines and matrix metalloproteinase-like enzymes (3). This complex inflammatory process may trigger remodeling in the corneal stroma, leading to an increase in corneal densitometry. In addition, medical treatment applied after chalazion excision in these patients may have contributed to the reduction of corneal densitometry values by eliminating infectious agents and inflammatory mediators and causing a decrease in conjunctival inflammation. However, the reason for corneal densitometry values not returning to normal after surgical excision remains unclear. These results are pre-sumambly related to the short follow-up period. In studies performed in patients undergoing refractive surgery, keratocyte activation that can persist for months after the intervention has been reported $(27,28)$. In addition, the researchers noted that the high corneal densitometry values observed in the keratitis areas during the active infection period were still higher than normal, although the keratitis area appeared to be complete- ly healed on biomicroscopic examination (29). The present study observed that corneal densitometry values decreased in the post-operative period and were similar to the values in the healthy control group. In addition, it was observed that corneal densitometry values were higher in anterior and total regions of the upper eyelid compared to lesions in the lower eyelid. This may be related to the biomechanical properties of the cornea, changes in the corneal structure in patients with chalazion, or more contact of the chalazion in the upper eyelid with the cornea due to gravity. This result, in addition to aberrometric changes in the cornea, may be another reason for the early excision of the upper eyelid chalazion.

This study had some limitations. First, a small number of patients included in this study. This result needs to be supported by a larger number of patients. Second, in vivo confocal microscopy was not provided to the participants to support these findings. Possible microstructural changes in the cornea in chalazion should be supported by in vivo confocal microscopic studies. Finally, in the present study, the patients were evaluated in the $\left.\right|^{\text {st }}$ post-operative month. Long-term results after excision should also be observed in these patients.

\section{Conclusion}

It was observed that some corneal aberration values and corneal densitometry values were higher in chalazion patients than in a healthy control group, and there was a decrease in corneal aberrations and densitometry values after surgical excision in this study. Although improvement was observed in densitometric and aberrometric values in the early period after excision, problems in optical quality may persist unless the predisposing factors causing chalazion development are completely eliminated.

\section{Disclosures}

Ethics Committee Approval: Diyarbakır Gazi Yaşargil Training and Research Hospital (08.11.2019/366).

Peer-review: Externally peer-reviewed.

Conflict of Interest: None declared.

Authorship Contributions: Involved in design and conduct of the study (HO, UD, MFA, YY); preparation and review of the study (HO, YY, MC); data collection (HO, UD, MFA); and statistical analysis (MC, HO).

\section{References}

I. Bagheri A, Hasani HR, Karimian F, Abrishami M, Yazdani S. Effect of chalazion excision on refractive error and corneal topography. Eur J Ophthalmol 2009;19:52 I-6. [CrossRef]

2. Nemet AY, Vinker S, Kaiserman I. Associated morbidity of chalazia. Cornea 20II;30:1376-8I. [CrossRef]

3. Otri A, Fares U, Al-Aqaba MA, Dua HS. Corneal densitometry 
as an indicator of corneal health. Ophthalmology 2012;1 1 9:50 I8. [CrossRef]

4. Oculus. Pentacam Instruction Manual. Wetzlar, Germany: Oculus; 2003. p. 5-43.

5. Ni Dhubhghaill S, Rozema JJ, Jongenelen S, Hidalgo IR, Zakaria $\mathrm{N}$, Tassignon MJ. Normative values for corneal densitometry analysis by Scheimpflug optical assessment. Invest Ophthalmol Vis Sci 2014;55:162-8. [CrossRef]

6. Liang L, Ding $X$, Tseng SCG. High prevalence of demodex brevis infestation in chalazia. Am J Ophthalmol 20I4;157:342-8.el.

7. Lin H, Li W, Dong N, Chen W, Liu J, Chen L, et al. Changes in corneal epithelial layer inflammatory cells in aqueous tear-deficient dry eye. Invest Ophthalmol Vis Sci 2010;51:122-8.

8. Villani E, Magnani F, Viola F, Santaniello A, Scorza R, Nucci P, et al. In vivo confocal evaluation of the ocular surface morpho-functional unit in dry eye. Optom Vis Sci 2013;90:576-86.

9. Montés-Micó R. Role of the tear film in the optical quality of the human eye. J Cataract Refract Surg 2007;33:163I-5.

10. Koh S, Maeda N, Ikeda C, Asonuma S, Mitamura H, Oie Y, et al. Ocular forward light scattering and corneal backward light scattering in patients with dry eye. Invest Ophthalmol Vis Sci 20I4;55:660I-6. [CrossRef]

I I. Fukuoka S, Arita R, Shirakawa R, Morishige N. Changes in meibomian gland morphology and ocular higher-order aberrations in eyes with chalazion. Clin Ophthalmol 2017;30; I 1:1031-8.

12. Meek KM, Newton RH. Organization of collagen fibrils in the corneal stroma in relation to mechanical properties and surgical practice. J Refract Surg 1999; 15:695-9. [CrossRef]

13. Hjortdal JO. Regional elastic performance of the human cornea. J Biomech 1996;29:931-42 [CrossRef]

14. Park YM, Lee JS. The effect of chalazion excision on corneal surface aberations. Contact lens Anterior Eye 2014;37:342-5.

15. Jin KW, Shin YJ, Hyan JY. Effect of chalazia on corneal astigmatizm: Large-sized chalazia in middle upper eyelids compress the cornea and induce the corneal astigmatizm. BMC Ophthalmology 2017;17:36. [CrossRef]

16. Sabermoghaddam AA, Zarei-Ghanavati S, Abrishami M. Effect of chalazion excision on ocular aberations. Cornea 2013;32:75760. [CrossRef]

17. Ilhan C, Yilmazoglu MO, Yilmazbas P. The effects of chalazion surgery on intraocular pressure and corneal topography. Int
Ophthalmol 2019;39:1055-9. [CrossRef]

18. Applegate RA, Thibos LN, Hilmantel G. Optics of aberroscopy and super vision. J Cataract refract Surg 200I;27:1093-107.

19. Cankaya AB, Tekin K, Kiziltoprak H, Karahan S, Yilmazbas P. Assessment of corneal backward light scattering in the healthy cornea and factors afecting corneal transparency. Jpn J Ophthalmol 2018;62:335-4l. [CrossRef]

20. Garzón N, Poyales F, Illarramendi I, Mendicute J, Jáñez Ó, Caro $\mathrm{P}$, et al. Corneal densitometry and its correlation with age, pachymetry, corneal curvature, and refraction. Int Ophthalmol 2017;37:1263-8. [CrossRef]

21. Shankar H, Taranath D, Santhirathelagan CT, Pesudovs K. Repeatability of corneal first-surface wavefront aberrations measured with Pentacam corneal topography. J Cataract Refract Surg 2008;34:727-34. [CrossRef]

22. Shankar H, Taranath D, Santhirathelagan CT, Pesudovs K. Anterior segment biometry with the Pentacam: comprehensive assessment of repeatability of automated measurements. J Cataract Refract Surg 2008;34:103-13. [CrossRef]

23. Baratz KH, McLaren JW, Maguire LJ, Hodge DO, McLaren JW. Corneal haze determined by confocal microscopy 2 years after Descemet stripping with endothelial keratoplasty for Fuchs corneal dystrophy. Arch Ophthalmol 2012;130:868-74.

24. Patel S, McLaren JW, Hodge DO, Bourne WM. The effect of corneal light scatter on vision after penetrating keratoplasty. Am J Ophthalmol 2008; 146:9/3-9. [CrossRef]

25. O'Donnell C, Wolffsohn JS. Grading of corneal transparency. Cont Lens Anterior Eye 2004;27:16I-70 [CrossRef]

26. Tanaka M, Dogru M, Takano Y, Miyake-Kashima M, Asano-Kato $\mathrm{N}$, Fukagawa $\mathrm{K}$, et al. The relation of conjunctival and corneal findings in severe ocular allergies. Cornea 2004;23:464-7.

27. Moilanen JA, Vesaluoma MH, Muller LJ, Tervo TM. Longterm corneal morphology after PRK by in vivo confocal microscopy. Invest Ophthalmol Vis Sci 2003;44:1064-9. [CrossRef]

28. Erie JC, Patel SV, McLaren JW, Hodge DO, Bourne WM. Keratocyte density in the human cornea after photorefractive keratectomy. Arch Ophthalmol 2003;121:770-6. [CrossRef]

29. Vemuganti GK, Reddy K, Iftekhar G, Garg P, Sharma S. Keratocyte loss in corneal infection through apoptosis: a histologic study of 59 cases. BMC Ophthalmol 2004;4: I6. [CrossRef] 